\title{
An Overview of Stem Cell Therapies for
}

\section{Parkinson's Disease}

\section{SARA FAOUR AND AARTHI ASHOK}

Department of Biological Sciences, University of Toronto Scarborough, Canada

\section{Abstract}

Parkinson's disease (PD) is referred to as a neurodegenerative disease which is a disease that targets specific brain regions and is characterized by neuronal death. PD is believed to be caused by the loss of nerve cells in the substantia nigra (SN), a dopamine releasing area. Current treatments are directed at alleviating pain symptoms and slowing down the progression of disease, however, no cure currently exists. Recent advances in stem cell therapies raise new possibilities to treat neurodegenerative diseases. Stem cells have the ability to differentiate into neural cells, so they could potentially be used to restore neurogenesis and neuroplasticity. There exist several cell types that can be applied in therapy including embryonic stem cells, neural stem cells, induced pluripotent stem cells, and mesenchymal stem cells. PD, which has localized neural degeneration to the SN, may serve as a better model for stem cell therapy and displays greater success when compared to other neurodegenerative diseases that spread to several brain regions. This review aims to discuss the several approaches used in stem cell therapy as well the current challenges and shortcomings of this cell-based therapy.

Keywords: neurodegenerative diseases, Parkinson's disease, substantia nigra, embryonic stem cells, neural stem cells, induced pluripotent stem cells, mesenchymal stem cells

\section{Disease Pathology}

Parkinson's disease (PD) is caused by the progressive loss of dopamine-producing neurons in the SN accompanied by the presence of Lewy bodies, which are formed by insoluble aggregates of a-synuclein (Zhu et al., 2016). These dopamine (DA) neurons project to the basal ganglia (the striatum) which is a region greatly correlated with motor control and function (Han et al., 2015). Consequently, decreased dopamine levels in the striatum lead to the common motor symptoms exhibited by a PD patient, which include muscle rigidity, tremors, bradykinesia and postural instability (Gugliandolo et al., 2017). PD is also associated with non-motor symptoms including depression, cognitive dysfunction, and sleep disorders (Chaudhuri et al., 2006). Approximately 95\% of PD cases are sporadic, as opposed to familial (Modi et al., 2016). The asynuclein gene, encoding a synaptic 
vesicle-associated protein that shows up in Lewy bodies, is a gene linked to the autosomal-dominant form of familial PD (Pu et al., 2012). Studies also noted changes in mitochondrial performance as a result of PD. For example, some motor symptoms were established in mice in response to genetic alterations of mitochondrial respiratory function (Kelly et al., 2014). Another hallmark of PD is neuroinflammation caused by the persistent activation of astrocytes and microglia through the chronic expression of cytokines and pro-inflammatory factors including tumour necrosis factor- $\alpha$ and interleukin-1 $\beta$ (Cucarian Hurtado et al., 2018).

Since the 1980s, there have been several successful clinical trials utilizing human fetal dopaminergic neurons (DAergic) to restore DA transmission: These neural transplants survive and integrate with the host brain neurons (W. Li et al., 2015). Follow-up PET scans showed evidence that these grafted neurons take up DA, and patients showed improved performance, reduced rigidity, and increased speed of motor movement. However, fetal cell transplantation has various ethical, technical, and practical limitations (Rhee et al., 2011). In addition, fetal tissue has limited availability, so there is an increased demand for an unlimited stem cell source to treat PD.

Given that PD involves the loss of DAergic neurons in the $\mathrm{SN}$, one intuitive approach would be cell replacement therapy. The particular focus would be on stem cells capable of differentiating into DAergic neurons, thus providing protection and promoting regeneration of the damaged neurons.

\section{Theory}

The theory behind using stem cells is not only for cell replacement therapy but also for stimulation of endogenous repair via paracrine effects. Injected stem cells can provide trophic support, which promotes the survival of the remaining cells (Kwak et al., 2018). Paracrine mediators resulting from transplantation of stem cells include neurotrophic factor, nerve growth factor, insulin growth factor-1, and vascular endothelial growth factor (Jin et al., 2002).

The objective of stem cell therapy entails the replacement of cells that have an essential neuronal function and enrichment of the cellular environment through the release of neurotrophic factors (Lunn et al., 2011). Model organisms include PD mice and non-human primates.

This review aims to discuss the different stem cell types and their possible implications in therapy for PD. This discussion will touch on advances in therapy that involve multiple animal models as well as recent human clinical trials. The limitations that accompany this therapy are also explored. For a stem cell therapy to be translated from the lab to 
patients, it goes through several stages. This includes in vitro characterization, animal models, clinical trials, patient enrollment, an operation, and a follow-up assessment (Lunn et al., 2011). If successful, this culminates in an FDAapproved stem cell therapy.

\section{Stem Cell Types}

Stem cells are cells that can self-renew and differentiate into any subtype, including neural cells. Selecting the appropriate stem cell type is the first step towards developing a successful stem cell therapy. When choosing stem cells it is important to consider various factors, as each type has advantages and disadvantages.

\section{Embryonic Stem Cells}

Embryonic stem cells (ESCs) are derived from the inner cell mass of blastocysts, can differentiate into three germ layers, and can develop into several cell types (Fu et al., 2015). Issues that arise with this cell type include ethical concerns, immune system complications, and potential tumour formation. This is because embryonic tissues are being used. ESCs are obtained from an embryo resulting from in vivo fertilization of an egg and a sperm donated for research purposes with informed consent (Vasic et al., 2019). Immune system complications are a result of allogenic transplants, and these cells also carry a greater risk of developing into tumours due to their enhanced replicative ability and pluripotency (Watanabe, 2018).

\section{Neural Stem Cells}

Neural stem cells (NSCs) are isolated either from fetal brains or specific regions in the adult brain. In adult tissue, NSCs are found mainly in the subventricular zone of the lateral walls of the ventricles and in the sub-granular zone of the hippocampal dentate gyrus of the brain (Vasic et al., 2019). These cells are multipotent and can replicate and differentiate based on induced environmental factors to give rise to cell types such as neurons, oligodendrocytes, or astrocytes (Shimada et al., 2012). The risk of tumour formation is reduced, and these cells can easily differentiate into neurons because of their specific lineage restriction ( $\mathrm{Fu}$ et al., 2015). Unfortunately, they fail to isolate in large numbers and cannot be maintained over long periods of time in vitro (Anderson et al., 2007), which limits their transplantation capacities.

\section{Induced Pluripotent Stem Cells}

Induced pluripotent stem cells (iPSCs) are unique because we can obtain their embryonic state by reprogramming adult cells with the addition of transcription factors. Fibroblasts are most commonly used because they are easy to obtain (Duncan \& Valenzuela, 2017). In 2006, the first successful study reprogrammed somatic cells (mouse fibroblasts) into an embryonic-like state using four 
transcription factors: Oct4, Sox2, Klf4, and Nanog (Takahashi \& Yamanaka, 2006). This discovery enriched the field of stem cells, and researchers have since attempted to optimize the protocol by reducing the number of transcription factors (W. Li et al., 2015). Because these cells are obtained directly from one's adult cells, the risk of immune rejection is minimized, and ethical issues are avoided. However, the process of obtaining them is inefficient: Many cells are lost, and it is time-consuming (Watanabe, 2018).

\section{Mesenchymal Stem Cells}

Mesenchymal stem cells (MSCs) are multipotent cells that can be harvested from various tissues such as umbilical cord blood or Wharton's jelly (gelatinous substance within the umbilical cord), bone marrow (BM-MSCs), and adipose tissue (Duncan \& Valenzuela, 2017). MSCs cannot differentiate into neural cells but rather induce neural recovery by producing trophic factors that in turn stimulate repair, endogenous neurogenesis, and modulation of inflammation (Liang et al., 2014). Immunomodulation is a unique property that allows cells to escape recognition by the host's immune response. MSCs are also capable of selfrenewal in vitro (Volkman \& Offen, 2017), with varying differentiation potentials depending on tissue location. They have a spindle-shaped morphology and can adhere easily to in vivo culture (Salem \& Thiemermann, 2010, as cited in Volkman \&
Offen, 2017). Vasic et al. (2019) observed that MSCs grown in culture greatly expanded while retaining their multipotent potential, thus generating high cell quantities. These were also shown to be safe in autologous transplantation and did not induce toxicity or tumours following transplantation into rodents and human patients. A particular benefit of MSCs is that they can be applied intravenously because they are able to cross the blood-brain barrier and travel to the injury site (Vasic et al., 2019). For the above reasons, MSCs are widely utilized in research.

The four stem cell types listed above are referred to as regenerative medicine therapies and are continuously monitored in clinical trials by the FDA (Watanabe, 2018). Table 1 summarizes the advantages and disadvantages of these various cell types.

\section{Method of Administration}

If stem cells were to be used in therapy, we would have to find an efficient way to administer them to the region of interest in the brain of PD patients. Methods of administration include the following: intravenous, intraarterial, intranasal, intrathecal (into spinal theca, a membrane that surrounds the spinal cord), or intracerebral, which entails stereotactic injections. Depending on the stem cell type used, these methods of administration would display varying rates of success. For example, MSCs, which are 
Table 1. Summary of the advantages and disadvantages of different stem cell types.

Embryonic stem cells (ESCS); neural stem cells (NSCs); induced pluripotent stem cells (iPSCs); mesenchymal stem cells (MSCs).

\begin{tabular}{|l|l|l|}
\hline \multicolumn{1}{|c|}{ Stem Cell Type } & \multicolumn{1}{|c|}{ Advantages } & \multicolumn{1}{c|}{ Disadvantages } \\
\hline ESCs & $\begin{array}{l}\text { High capacity of self-renewal } \\
\text { Pluripotent }\end{array}$ & $\begin{array}{l}\text { Ethical issues (isolated from fetus or } \\
\text { blastocyst) } \\
\text { Uncontrolled differentiation (tumorigenic } \\
\text { potential) }\end{array}$ \\
\hline NSCs & Multipotent & Poor survival \\
\hline iPSCs & $\begin{array}{l}\text { Autologous transplantation (minimizing } \\
\text { rejection risk) } \\
\text { Pluripotent } \\
\text { Low risk of tumour formation }\end{array}$ & $\begin{array}{l}\text { Possible pathological phenotype (increase } \\
\text { tau phosphorylation etc.) } \\
\text { Difficult to preserve and proliferate for } \\
\text { long periods }\end{array}$ \\
\hline MSCs & $\begin{array}{l}\text { Easy handling } \\
\text { Multipotent } \\
\text { Intravenous application } \\
\text { Immunomodulation properties }\end{array}$ & Limited neuronal differentiation \\
\hline
\end{tabular}

more adapted to crossing the blood-brain barrier, have been successfully introduced in animal models with all these techniques, whereas it seems that a stereotactic approach is best for NSCs (Gennai et al., 2015). Furthermore, timing is an essential factor to consider. In injuries that require early administration, allogeneic sources, which are more readily available, would be used instead of autologous sources. Dosing is another variable to take into account. Two things to consider are the minimum number of required cells and whether multiple doses provide an enhanced effect (Watanabe, 2018). A few studies are beginning to investigate dosing. However, it seems that it varies based on injury-related variables and patient-specific differences. All these factors will differ from patient to patient and must be considered as a whole in order to develop successful therapies.

\section{Overview of Current PD Therapies}

Currently, there is no cure for PD and available treatments aim to replace DA using L-dihydroxyphenylalanine (L-DOPA) and/or DA receptor agonists (Zhu et al., 2016). These therapies improve symptoms during the early stages of the disease; however, this is gradually lost with longterm treatment. In addition, L-DOPA has side effects such as drug-induced dyskinesias (involuntary muscle movements). L-DOPA does not delay the loss of DA neurons and cannot recover the lost ones. DA replacement drugs such as the DA agonist levodopa increase DA levels (Yiannopoulou \& Papageorgiou, 2013), and DA inhibitors like carbidopa reduce $D A$ degradation in the peripheral blood (Han et al., 2015). Another type of treatment includes deep brain stimulation to the nucleus subthalamus (Limousin et 
al., 1995). However, these treatments cannot stop disease progression, so we can realize the need for the development of a regenerative therapy for PD.

\section{Stem Cell Therapy in PD}

For a stem cell therapy to be successful, it must restore DA in lacking neurons of the $\mathrm{SN}$ and consequently alleviate the motor symptoms associated with PD. The therapy should enable 100,000 or more DA neurons to survive long term, and the grafted cells should re-establish a dense terminal network throughout the striatum to functionally integrate into the host's neural circuits (Fu et al., 2015).

\section{Embryonic Stem Cell Therapy}

Embryonic stem cells (ESCs) have two main safety concerns: risk of tumour formation and neural overgrowth (Kim et al., 2013). Studies have demonstrated the efficacy of this cell type in animal models of PD. In a study by Cho et al. (2008), functional DA neurons generated from human ESCs were grafted into a rat model of PD, which subsequently exhibited behavioural recovery. In addition, this method generated spherical neural masses that allowed them to obtain a large number of DA neurons within a short time period and minimized potential contamination from unwanted cells and pathogens coming from the feeder layer (Cho et al., 2008). This differentiation enhances the efficacy of the treatment and reduces the potential for tumour formation. These studies set a precedent for future clinical applications. Furthermore, in a monkey model of PD, transplantation of midbrain DA neurons derived from ESCs led to proper neuronal integration and lack of neural overgrowth (Kriks et al., 2011).

\section{Neural Stem Cell Therapy}

Neural stem cells (NSCs) are present in the adult mammalian brain but do not provide adequate repair due to location-based restrictions, their limited number, and a microenvironment that does not provide neuronal differentiation support (Gonzalez et al., 2016). There is limited literature on NSC transplantation in PD. Nevertheless, transplantation of NSCs may provide a promising strategy for treating this disease via cell replacement, the release of specific neurotransmitters, and the production of neurotrophic factors that protect injured neurons and promote neuronal growth (Kim et al., 2013). In a study by Yasuhara et al. (2006), transplantation of human NSCs cloned by gene transfer, into 6-hydroxydopaminelesioned (6-OHDA) striatum of rats (PD model) led to a significant improvement in parkinsonian behavioural symptoms when compared to controls. Further experiments demonstrated that the neuroprotective effect against lack of DA was established both in vitro and in vivo because of trophic factor secretion and neuronal differentiation (Yasuhara et al., 2006). In addition, engineering NSCs to produce LDOPA and transplanting them into a rat 
model of PD led to increased L-DOPA production in vivo and induced functional recovery (Kim et al., 2006).

\section{Induced Pluripotent Stem Cell Therapy}

Embryonic and neural transplantations are limited by the availability of tissues, potential immune rejection, and ethical concerns that don't apply to induced pluripotent stem cells (iPSCs; Xiao et al., 2016). For PD, it is possible to direct somatic cells to become DAergic neurons using transcription factors. In a study by Wernig et al. (2008), iPSCs grafted in adult mice differentiated into DA neurons and resulted in improved motor functions. The risk of tumour formation was minimized by separating contaminated pluripotent cells from committed neural cells utilizing fluorescence-activated cell sorting (Wernig et al., 2008). Another study was successful upon DA neuron transplantation into rat striatum and showed locomotive function recovery five months posttreatment (Yang et al., 2008). The improvement in behaviour was correlated to DA presence, specifically in SN, demonstrating the importance of this region in functional repair (Yang et al., 2008). In addition, transplantation of DA derived from protein-based human iPSCs into rat models with striatal lesions significantly improved motor deficits (Rhee et al., 2011). These studies show that human DA neurons produced in vitro can successfully integrate into brain regions. Moving on to higher-order model organisms, a two-year long study involving non-human primates found an improvement in motor activity and function and extensive cell survival following iPSC-derived DAergic neuron transplantation (Hallett et al., 2015). Developing an effective therapy utilizing iPSCs depends on optimizing in vitro production of iPSC-derived DA neurons and avoiding potential tumour growth in vivo (Kim et al., 2013). We can use this for basic research mechanisms, including drug discovery and cell-based therapy utilizing autologous donor materials ( $\mathrm{Pu}$ et al., 2012). An issue that rises with this therapy is grafted neurons developing Lewy bodies in some PD patients ( $\mathrm{Li}$ et al., 2008). Components of Lewy bodies (e.g., asynuclein) found in the brain of PD patients may cause changes in the graft through a prion-like mechanism ( $\mathrm{Pu}$ et al., 2012).

\section{Mesenchymal Stem Cell Therapy}

In one study, human mesenchymal stem cells (MSCs) that were transplanted into the striatum of rats with 6-OHDA (dopamine analogue) lesions survived 23 days post-transplantation (Cova et al., 2010). Survival is directly influenced by the surrounding environment, and the grafted cells can regionally sustain the survival of nigral DA neurons and enhance neurogenesis in the subventricular zone (Cova et al., 2010). The persistent release of cytokines by MSCs in vivo managed to mitigate the effects of neurodegeneration induced by the 6-OHDA lesion. These 
results provide the potential for MSC use in the promotion of endogenous repair mechanisms that can be beneficial for PD treatment. To address the low differentiation potential of MSCs, UC-MSCs (umbilical cord-derived MSCs) were cultured with a fibroblast growth factor, which increased neuronal differentiation, and this enhanced apomorphine-induced (dopamine agonist) rotations in rats with 6-OHDA lesions (Fu et al., 2006).

\section{Clinical Trials in PD}

Seven PD patients received unilateral transplantation of autologous bone marrow mesenchymal stem cells (BMMSCs). The cells were transplanted into the subventricular zone using stereotaxic surgery (Venkataramana et al., 2010). Results indicated an improvement for three out of seven patients, as measured by the Unified Parkinson's Disease Rating Scale (UPDRS). UPDRS is a clinical rating scale for PD and is used to assess the efficacy of new treatments. They verified the safety of the protocol but were unable to demonstrate the efficacy of the treatment due to the small number of patients enrolled and the uncontrolled nature of the trial (Venkataramana et al., 2010). Another clinical trial transplanted BM-MSCs treated with basic fibroblast growth factor unilaterally into the ventricular zone of advanced PD patients, who showed modest clinical improvement at 12 months and no formation of tumours (Venkataramana et al., 2010). The Center for iPS Cell Research and Application in
Japan started two clinical trials. The first is a phase I/II study investigating the safety and efficacy of transplanting human iPSC-derived DAergic neurons into the putamen (a region in the striatum) of PD patients. The second is a phase III study evaluating the safety and efficacy of tacrolimus (an immunosuppressive drug used for allogeneic transplants) in the iPSC-based therapy to treat PD (Fan et al., 2020). Table 2 summarizes recent and ongoing clinical trials.

\section{Discussion \& Perspectives}

Stem cell therapy has great potential for the treatment of neurodegenerative diseases. The theory behind this treatment is that these transplanted cells will differentiate into neuronal and glial cells to replace the damaged ones and will act in a paracrine manner by secreting neuroprotective agents that stimulate endogenous repair mechanisms. Despite tremendous progress in the understanding of stem cell treatments, much is still unknown. This includes challenges in directing differentiation to a specific lineage of interest. Differentiation is not always efficient, as we obtain a mixture of cells, which decreases the efficacy of the treatment. In vitro expansion of cells also results in accumulated mutations that not only increase the risk of tumorigenesis but also impair differentiation into the desired cell type (Bhagavati, 2015). The goal of transplanted cells is to integrate into neural circuits in the host environment. However, this is not as straightforward as 
Table 2. Recent clinical trials utilizing stem cell therapy in Parkinson's disease.

\begin{tabular}{|l|l|l|l|l|}
\hline Author & Date & Clinical Trial Title & $\begin{array}{l}\text { Identifier } \\
\text { No. }\end{array}$ & URL \\
\hline Jamali, F. & $\begin{array}{l}(2018, \text { Sep } \\
25-) .\end{array}$ & $\begin{array}{l}\text { Use of MSCs } \\
\text { differentiated into NSCs } \\
\text { in people with PD. }\end{array}$ & $\begin{array}{l}\text { Identifier } \\
\text { NCTO368 } \\
4122 .\end{array}$ & $\begin{array}{l}\text { https://clinicaltria } \\
\text { Is.gov/ct2/show/ } \\
\text { NCT03684122 }\end{array}$ \\
\hline University of Jordan. & $\begin{array}{l}(2019, \text { Oct } \\
31-) .\end{array}$ & $\begin{array}{l}\text { Parkinson's disease } \\
\text { therapy using cell } \\
\text { technology }\end{array}$ & $\begin{array}{l}\text { Identifier } \\
\text { NCT0414 } \\
6519 .\end{array}$ & $\begin{array}{l}\text { https://clinicaltria } \\
\text { Is.gov/ct2/show/ } \\
\text { NCT04146519 }\end{array}$ \\
\hline Boika, A. et al. & $\begin{array}{l}(2017, \text { Nov } \\
17-2019, \\
\text { Sep 18) }\end{array}$ & $\begin{array}{l}\text { Allogenic BM-MSCs } \\
\text { therapy for Idiopathic } \\
\text { PD. }\end{array}$ & $\begin{array}{l}\text { Identifier } \\
\text { NCTO261 } \\
1167 .\end{array}$ & $\begin{array}{l}\text { https://clinicaltria } \\
\text { Is.gov/ct2/show/ } \\
\text { NCT02611167 }\end{array}$ \\
\hline Schiess, M. & & &
\end{tabular}

it seems, as research needs to better understand the mechanisms of integration and how to improve them.

Experiments done on rodent models yield promising results and have paved the way for clinical trials. Unfortunately, this translation has not been as smooth. Results of clinical trials have been problematic and have yielded inconsistent results. Currently, clinical trials are in stage I/II with the main goal of investigating safety. Several problems arise including issues with participant enrollment and selection, time of transplantation, stage of the disease, gender differences, and post-trial monitoring. Mode of engraftment and immunosuppression levels are also factors at play. The absence of immunosuppression has also led to poor outcomes in clinical trials (Freed et al., 2001; Olanow et al., 2003). The immune system will exert negative effects during transplantation, and it seems that a combination of grafting and immunosuppression will be needed to optimize results.

Future studies should aim to examine the optimal dosing of immunosuppressants and the duration of treatment. Prior to starting clinical trials, more comprehensive research should focus on crucial factors such as cell type, cell source, method of administration, longterm safety, and efficacy. Larger studies are also essential to make conclusions regarding the effectiveness of treatments. It is possible that a synergy of methods needs to be employed in treatment strategies, involving exogenous neuroreplacement, endogenous neurogenesis, and various pharmacological agents.

In PD, patient selection is an important factor as it seems that those with genetic origins of PD may respond better to this cell-based therapy (Xiao et al., 2016). Another concern is graft-induced dyskinesia in PD patients, which may take place post-transplantation. There have also been reports of PD pathology being transferred from host to grafts, which is 
indicative of a prion-like mechanism for PD (Visanji et al., 2013). Despite these adverse effects, transplantation will still provide a longer lifespan than any current medication can provide.

It is important to understand that statistically significant changes are not always equivalent to clinically meaningful changes, and we need to focus on identifying the latter. Generally, studies do not account for the pairing of rehabilitation therapies even though it is very likely that these will impact the outcome of clinical trials. Aravamudhan and Bellamkonda (2011) hypothesized that a combination of cell replacement, drug delivery, neurorehabilitation, and other interventions is required to promote activation of damaged neuronal circuits. The authors reviewed papers that consider such combinations and found common themes.

Upon examination of the current literature, there are some studies that distinguish themselves and seem to present promising data. Two papers by Fan et al. (2002) and Zeng and Couture (2013) present the current state of the field and future prospects. Another paper by Volkman and Offen (2017), focuses on MSCs, which seem to be promising, as they are most commonly utilized in clinical trials.

In conclusion, it will take a long time before any consensus is reached, but studies can provide a framework to test the efficiency of stem cell therapies for neurodegenerative diseases. It seems that more is known regarding PD, so if therapy were to be successful, it would likely be for PD before other neurodegenerative diseases. The results of ongoing studies will potentially provide answers on the efficiency of stem cell therapy in PD patients.

A hallmark of stem cell therapy is its restorative function and trophic ability, which extend beyond those of any current drugs available on the market. Hence, it is essential that studies continue to investigate the usage of stem cells for treating PD. 


\section{References}

Aravamudhan, S., \& Bellamkonda, R. V. (2011). Toward a Convergence of Regenerative Medicine, Rehabilitation, and Neuroprosthetics. Journal of Neurotrauma, 28(11), $2329-$ 2347. https://doi.org/10.1089/neu.2010.1542

Bhagavati, S. (2015). Stem Cell Therapy: Challenges Ahead. Indian Journal of Pediatrics, 82(3), 286-291. https://doi.org/10.1007/s12098-014-1521-5

Bissonnette, C. J., Lyass, L., Bhattacharyya, B. J., Belmadani, A., Miller, R. J., \& Kessler, J. A. (2011). The controlled generation of functional basal forebrain cholinergic neurons from human embryonic stem cells. Stem Cells (Dayton, Ohio), 29(5), 802-811. https://doi.org/10.1002/stem.626

Chaudhuri, K. R., Healy, D. G., \& Schapira, A. H. (2006). Non-motor symptoms of Parkinson's disease: Diagnosis and management. The Lancet Neurology, 5(3), 235-245. https://doi.org/10.1016/S1474-4422(06)70373-8

Cova, L., Armentero, M.-T., Zennaro, E., Calzarossa, C., Bossolasco, P., Busca, G., Lambertenghi Deliliers, G., Polli, E., Nappi, G., Silani, V., \& Blandini, F. (2010). Multiple neurogenic and neurorescue effects of human mesenchymal stem cell after transplantation in an experimental model of Parkinson's disease. Brain Research, 1311, 12-27. https://doi.org/10.1016/j.brainres.2009.11.041

Cucarian Hurtado, J. D., Berrio Sanchez, J. P., Nunes, R. B., \& de Oliveira, A. A. (2018). Stem Cell Transplantation and Physical Exercise in Parkinson's Disease, a Literature Review of Human and Animal Studies. Stem Cell Reviews and Reports, 14(2), 166-176. https://doi.org/10.1007/s12015-017-9798-1

Dickson, D. W. (2012). Parkinson's Disease and Parkinsonism: Neuropathology. Cold Spring Harbor Perspectives in Medicine, 2(8). https://doi.org/10.1101/cshperspect.a009258

Duncan, T., \& Valenzuela, M. (2017). Alzheimer's disease, dementia, and stem cell therapy. Stem Cell Research \& Therapy, 8, 111. https://doi.org/10.1186/s13287-017-0567-5

Fan, Y., Winanto, \& Ng, S.-Y. (2020). Replacing what's lost: A new era of stem cell therapy for Parkinson's disease. Translational Neurodegeneration, 9(1), 2. https://doi.org/10.1186/s40035-019-0180-x 
Freed, C. R., Greene, P. E., Breeze, R. E., Tsai, W.-Y., DuMouchel, W., Kao, R., Dillon, S., Winfield, H., Culver, S., Trojanowski, J. Q., Eidelberg, D., \& Fahn, S. (2001). Transplantation of Embryonic Dopamine Neurons for Severe Parkinson's Disease. New England Journal of Medicine, 344(10), 710-719. https://doi.org/10.1056/NEJM200103083441002

Fu, M.-H., Li, C.-L., Lin, H.-L., Chen, P.-C., Calkins, M. J., Chang, Y.-F., Cheng, P.-H., \& Yang, S.-H. (2015). Stem cell transplantation therapy in Parkinson's disease. Springerplus, 4, 597. https://doi.org/10.1186/s40064-015-1400-1

Gennai, S., Monsel, A., Hao, Q., Liu, J., Gudapati, V., Barbier, E. L., \& Lee, J. W. (2015). CellBased therapy for traumatic brain injury. BJA: British Journal of Anaesthesia, 115(2), 203212. https://doi.org/10.1093/bja/aev229

Gonzalez, R., Hamblin, M. H., \& Lee, J.-P. (2016). Neural Stem Cell Transplantation and CNS Diseases. Cns \& Neurological Disorders-Drug Targets, 15(8), 881-886. https://doi.org/10.2174/1871527315666160815164247

Gugliandolo, A., Bramanti, P., \& Mazzon, E. (2017). Mesenchymal stem cell therapy in Parkinson's disease animal models. Current Research in Translational Medicine, 65(2), 5160. https://doi.org/10.1016/j.retram.2016.10.007

Hallett, P. J., Deleidi, M., Astradsson, A., Smith, G. A., Cooper, O., Osborn, T. M., Sundberg, M., Moore, M. A., Perez-Torres, E., Brownell, A.-L., Schumacher, J. M., Spealman, R. D., \& Isacson, O. (2015). Successful function of autologous iPSC-derived dopamine neurons following transplantation in a non-human primate model of Parkinson's disease. Cell Stem Cell, 16(3), 269-274. https://doi.org/10.1016/j.stem.2015.01.018

Han, F., Baremberg, D., Gao, J., Duan, J., Lu, X., Zhang, N., \& Chen, Q. (2015). Development of stem cell-based therapy for Parkinson's disease. Translational Neurodegeneration, 4, UNSP 16. https://doi.org/10.1186/s40035-015-0039-8

Jin, K., Zhu, Y., Sun, Y., Mao, X. O., Xie, L., \& Greenberg, D. A. (2002). Vascular endothelial growth factor (VEGF) stimulates neurogenesis in vitro and in vivo. Proceedings of the National Academy of Sciences of the United States of America, 99(18), 11946-11950. https://doi.org/10.1073/pnas.182296499 
Kelly, N. A., Ford, M. P., Standaert, D. G., Watts, R. L., Bickel, C. S., Moellering, D. R., Tuggle, S. C., Williams, J. Y., Lieb, L., Windham, S. T., \& Bamman, M. M. (2014). Novel, high-intensity exercise prescription improves muscle mass, mitochondrial function, and physical capacity in individuals with Parkinson's disease. Journal of Applied Physiology, 116(5), 582-592. https://doi.org/10.1152/japplphysiol.01277.2013

Kim, H. J., Seo, S. W., Chang, J. W., Lee, J. I., Kim, C. H., Chin, J., Choi, S. J., Kwon, H., Yun, H. J., Lee, J. M., Kim, S. T., Choe, Y. S., Lee, K.-H., \& Na, D. L. (2015). Stereotactic brain injection of human umbilical cord blood mesenchymal stem cells in patients with Alzheimer's disease dementia: A phase 1 clinical trial. Alzheimer's \& Dementia: Translational Research \& Clinical Interventions, 1(2), 95-102. https://doi.org/10.1016/j.trci.2015.06.007

Kim, S. U., Lee, H. J., \& Kim, Y. B. (2013). Neural stem cell-based treatment for neurodegenerative diseases. Neuropathology, 33(5), $491-504$. https://doi.org/10.1111/neup.12020

Kim, S. U., Park, I. H., Kim, T. H., Kim, K. S., Choi, H. B., Hong, S. H., Bang, J. H., Lee, M. A., Joo, I. S., Lee, C. S., \& Kim, Y. S. (2006). Brain transplantation of human neural stem cells transduced with tyrosine hydroxylase and GTP cyclohydrolase 1 provides functional improvement in animal models of Parkinson disease. Neuropathology: Official Journal of the Japanese Society of Neuropathology, 26(2), 129-140. https://doi.org/10.1111/j.14401789.2006.00688.x

Kriks, S., Shim, J.-W., Piao, J., Ganat, Y. M., Wakeman, D. R., Xie, Z., Carrillo-Reid, L., Auyeung, G., Antonacci, C., Buch, A., Yang, L., Beal, M. F., Surmeier, D. J., Kordower, J. H., Tabar, V., \& Studer, L. (2011). Dopamine neurons derived from human ES cells efficiently engraft in animal models of Parkinson's disease. Nature, 480(7378), 547-551. https://doi.org/10.1038/nature10648

Kwak, K.-A., Lee, S.-P., Yang, J.-Y., \& Park, Y.-S. (2018). Current Perspectives regarding Stem Cell-Based Therapy for Alzheimer's Disease. Stem Cells International, 6392986. https://doi.org/10.1155/2018/6392986

Lee, H. J., Lim, I. J., Park, S. W., Kim, Y. B., Ko, Y., \& Kim, S. U. (2012). Human Neural Stem Cells Genetically Modified to Express Human Nerve Growth Factor (NGF) Gene Restore Cognition in the Mouse with Ibotenic Acid-Induced Cognitive Dysfunction. Cell Transplantation, 21(11), 2487-2496. https://doi.org/10.3727/096368912X638964 
Lee, I.-S., Jung, K., Kim, I.-S., Lee, H., Kim, M., Yun, S., Hwang, K., Shin, J. E., \& Park, K. I. (2015). Human neural stem cells alleviate Alzheimer-like pathology in a mouse model. Molecular Neurodegeneration, 10(1), 38. https://doi.org/10.1186/s13024-015-0035-6

Li, J.-Y., Englund, E., Holton, J. L., Soulet, D., Hagell, P., Lees, A. J., Lashley, T., Quinn, N. P., Rehncrona, S., Björklund, A., Widner, H., Revesz, T., Lindvall, O., \& Brundin, P. (2008). Lewy bodies in grafted neurons in subjects with Parkinson's disease suggest host-to-graft disease propagation. Nature Medicine, 14(5), 501-503. https://doi.org/10.1038/nm1746

Li, W., Chen, S., \& Li, J.-Y. (2015). Human induced pluripotent stem cells in Parkinson's disease: A novel cell source of cell therapy and disease modeling. Progress in Neurobiology, 134, 161-177. https://doi.org/10.1016/j.pneurobio.2015.09.009

Limousin, P., Pollak, P., Benazzouz, A., Hoffmann, D., Le Bas, J. F., Broussolle, E., Perret, J. E., \& Benabid, A. L. (1995). Effect of parkinsonian signs and symptoms of bilateral subthalamic nucleus stimulation. Lancet (London, England), 345(8942), 91-95. https://doi.org/10.1016/s0140-6736(95)90062-4

Liu, Y., Weick, J. P., Liu, H., Krencik, R., Zhang, X., Ma, L., Zhou, G., Ayala, M., \& Zhang, S.C. (2013). Medial ganglionic eminence-like cells derived from human embryonic stem cells correct learning and memory deficits. Nature Biotechnology, 31(5), 440-447. https://doi.org/10.1038/nbt.2565

Lunn, J. S., Sakowski, S. A., Hur, J., \& Feldman, E. L. (2011). Stem cell technology for neurodegenerative diseases. Annals of Neurology, 70(3), 353-361. https://doi.org/10.1002/ana.22487

National Library of Medicine (U.S.). (2017, Nov - 2019, Sep). Allogenic BM-MSCs therapy for Idiopathic PD. Identifier NCT02611167. https://clinicaltrials.gov/ct2/show/NCT02611167

National Library of Medicine (U.S.). (2018. Sep - ). Use of MSCs differentiated into NSCs in people with PD. Identifier NCT03684122. https://clinicaltrials.gov/ct2/show/NCT03684122

National Library of Medicine (U.S.). (2019, Oct - ). Parkinson's disease therapy using cell technology. Identifier NCT04146519. https://clinicaltrials.gov/ct2/show/NCT04146519 
Olanow, C. W., Goetz, C. G., Kordower, J. H., Stoessl, A. J., Sossi, V., Brin, M. F., Shannon, K. M., Nauert, G. M., Perl, D. P., Godbold, J., \& Freeman, T. B. (2003). A double-blind controlled trial of bilateral fetal nigral transplantation in Parkinson's disease. Annals of Neurology, 54(3), 403-414. https://doi.org/10.1002/ana.10720

Pu, J., Jiang, H., Zhang, B., \& Feng, J. (2012). Redefining Parkinson's Disease Research Using Induced Pluripotent Stem Cells. Current Neurology and Neuroscience Reports, 12(4), 392 - 398. https://doi.org/10.1007/s11910-012-0288-1

Rhee, Y.-H., Ko, J.-Y., Chang, M.-Y., Yi, S.-H., Kim, D., Kim, C.-H., Shim, J.-W., Jo, A.-Y., Kim, B.-W., Lee, H., Lee, S.-H., Suh, W., Park, C.-H., Koh, H.-C., Lee, Y.-S., Lanza, R., Kim, K.-S., \& Lee, S.-H. (2011). Protein-based human iPS cells efficiently generate functional dopamine neurons and can treat a rat model of Parkinson disease. The Journal of Clinical Investigation, 121(6), 2326-2335. https://doi.org/10.1172/JCI45794

Shimada, I. S., LeComte, M. D., Granger, J. C., Quinlan, N. J., \& Spees, J. L. (2012). SelfRenewal and Differentiation of Reactive Astrocyte-Derived Neural Stem/Progenitor Cells Isolated from the Cortical Peri-Infarct Area after Stroke. Journal of Neuroscience, 32(23), 7926-7940. https://doi.org/10.1523/JNEUROSCI.4303-11.2012

Takahashi, K., \& Yamanaka, S. (2006). Induction of pluripotent stem cells from mouse embryonic and adult fibroblast cultures by defined factors. Cell, 126(4), 663-676. https://doi.org/10.1016/j.cell.2006.07.024

Vasic, V., Barth, K., \& Schmidt, M. H. H. (2019). Neurodegeneration and NeuroRegeneration-Alzheimer's Disease and Stem Cell Therapy. International Journal of Molecular Sciences, 20(17). https://doi.org/10.3390/ijms20174272

Venkataramana, N. K., Kumar, S. K. V., Balaraju, S., Radhakrishnan, R. C., Bansal, A., Dixit, A., Rao, D. K., Das, M., Jan, M., Gupta, P. K., \& Totey, S. M. (2010). Open-labeled study of unilateral autologous bone-marrow-derived mesenchymal stem cell transplantation in Parkinson's disease. Translational Research, 155(2), 62-70. https://doi.org/10.1016/j.trsl.2009.07.006

Visanji, N. P., Brooks, P. L., Hazrati, L.-N., \& Lang, A. E. (2013). The prion hypothesis in Parkinson's disease: Braak to the future. Acta Neuropathologica Communications, 1(1), 1-12. https://doi.org/10.1186/2051-5960-1-2 
Volkman, R., \& Offen, D. (2017). Concise Review: Mesenchymal Stem Cells in Neurodegenerative Diseases. Stem Cells, 35(8), 1867-1880. https://doi.org/10.1002/stem.2651

Watanabe, T. K. (2018). A Review of Stem Cell Therapy for Acquired Brain Injuries and Neurodegenerative Central Nervous System Diseases. $P M \& R$, 10(9), S151-S156. https://doi.org/10.1016/j.pmrj.2018.07.008

Wernig, M., Zhao, J.-P., Pruszak, J., Hedlund, E., Fu, D., Soldner, F., Broccoli, V., Constantine-Paton, M., Isacson, O., \& Jaenisch, R. (2008). Neurons derived from reprogrammed fibroblasts functionally integrate into the fetal brain and improve symptoms of rats with Parkinson's disease. Proceedings of the National Academy of Sciences, 105(15), 5856-5861. https://doi.org/10.1073/pnas.0801677105

Xiao, B., Ng, H. H., Takahashi, R., \& Tan, E.-K. (2016). Induced pluripotent stem cells in Parkinson's disease: Scientific and clinical challenges. Journal of Neurology, Neurosurgery \& Psychiatry, 87(7), 697-702. https://doi.org/10.1136/jnnp-2015-312036

Yang, D., Zhang, Z.-J., Oldenburg, M., Ayala, M., \& Zhang, S.-C. (2008). Human Embryonic Stem Cell-Derived Dopaminergic Neurons Reverse Functional Deficit in Parkinsonian Rats. Stem Cells (Dayton, Ohio), 26(1), 55-63. https://doi.org/10.1634/stemcells.2007-0494

Yasuhara, T., Matsukawa, N., Hara, K., Yu, G., Xu, L., Maki, M., Kim, S. U., \& Borlongan, C. V. (2006). Transplantation of human neural stem cells exerts neuroprotection in a rat model of Parkinson's disease. The Journal of Neuroscience: The Official Journal of the Society for Neuroscience, 26(48), 12497-12511. https://doi.org/10.1523/JNEUROSCI.3719-06.2006

Yiannopoulou, K. G., \& Papageorgiou, S. G. (2013). Current and future treatments for Alzheimer's disease. Therapeutic Advances in Neurological Disorders, 6(1), 19-33. https://doi.org/10.1177/1756285612461679

Zeng, X., \& Couture, L. A. (2013). Pluripotent stem cells for Parkinson's disease: Progress and challenges. Stem Cell Research \& Therapy, 4, 25. https://doi.org/10.1186/scrt173

Zhu, B., Caldwell, M., \& Song, B. (2016). Development of stem cell-based therapies for Parkinson'sdisease. International Journal of Neuroscience, 126(11), 955-962. https://doi.org/10.3109/00207454.2016.1148034 